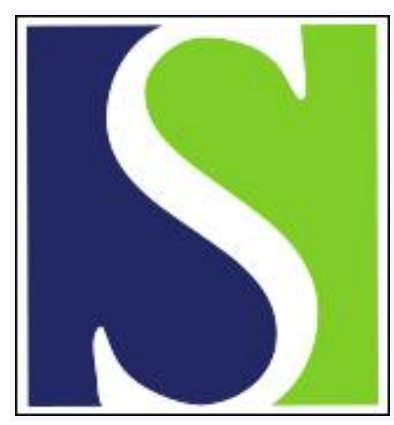

Scand J Work Environ Health 2005;31(4):291-299

https://doi.org/10.5271/sjweh.885

Issue date: Aug 2005

Long-term effect of occupational noise on the risk of coronary heart disease

by Virkkunen $\mathrm{H}$, Kauppinen T, Tenkanen L

Affiliation: Tampere School of Public Health, FIN-30104 University of Tampere, Tampere, Finland. hanna.virkkunen@uta.fi

The following articles refer to this text: 2007;33(6):425-434;

2007;33(6):470-478; 2012;38(1):19-26; 2012;38(1):1-3

Key terms: coronary heart disease; follow-up; Helsinki Heart Study; job-exposure matrix; long-term effect; longitudinal study; occupational noise; register linkage; risk

This article in PubMed: www.ncbi.nlm.nih.gov/pubmed/16161712

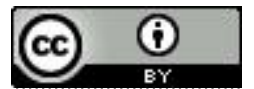




\title{
Long-term effect of occupational noise on the risk of coronary heart disease
}

\author{
by Hanna Virkkunen, MSc, ${ }^{1,2}$ Timo Kauppinen, PhD, ${ }^{3}$ Leena Tenkanen, PhD ${ }^{1,2}$
}

\begin{abstract}
Virkkunen H, Kauppinen T, Tenkanen L. Long-term effect of occupational noise on the risk of coronary heart disease. Scand J Work Environ Health 2005;31(4):291-199.

Objectives The aim of the study was to investigate the short- and long-term effects of occupational exposure to continuous and impulse noise on the risk of CHD.

Methods The effect of noise on CHD was studied among 6005 Finnish middle-aged industrially employed men (part of the screeners in the Helsinki Heart Study) in a prospective 18-year follow-up study. The CHD end points (codes 410-414 in the ninth revision of the International Classification of Diseases and codes I20-I25 in the tenth revision) were obtained from official Finnish registers. The Finnish job-exposure matrix FINJEM provided estimates of the proportion of exposed persons and the mean level of exposure among those exposed by occupation. The relative risks (RR) of CHD and the $95 \%$ confidence intervals (95\% CI) for noise exposure were calculated from Cox's proportional hazard models with adjustment for some other risk factors of CHD.

Results The short-term (9-year follow-up) relative risk of CHD for the combined noise (continuous noise exceeding 80 decibels and impulse noise) was 1.38 (95\% CI 1.04-1.82), and the long-term (18-year follow-up) RR was 1.54 (95\% CI 1.28-1.86). For blue-collar workers the corresponding estimates were 1.11 (95\% CI 0.821.51 ) and 1.29 (95\% CI 1.05-1.57). Adjustment for other relevant risk factors did not materially change the results. Conclusions In our long-term follow-up of industrially employed men, exposure to noise, especially to impulse noise, was associated with a moderate, but statistically significant increase in CHD risk that persisted even after the workers had passed the age of retirement.
\end{abstract}

Key terms follow-up; Helsinki Heart Study; job-exposure matrix; longitudinal study; register linkage.

Noise is a common environmental and occupational element in today's urban and industrialized societies. The health effects of noise exposure have been widely studied for decades. In addition to its effect on hearing, noise may cause psychological or mental strain, annoyance, sleep disturbances, and impairment of performance, and it may enhance the development of hypertension and cardiovascular diseases (1-3). There is a multitude of studies on the association between occupational noise and blood pressure. In their review article, Stansfeld et al (4) concluded that the findings to date suggest an association between occupational noise and hypertension. In a meta-analysis of studies published before 2000, van Kempen et al (5) concluded that a significant increase in systolic blood pressure was evident for occupational noise exposure although there were also contrary findings. The finding that the effect of noise exposure on blood pressure depended on job complexity was considered to have had some influence on the contrasting results (6).
Even while hypertension is one of the principal risk factors for coronary heart disease (CHD), few studies have focused on the association between occupational noise and CHD, and cohort studies in this domain are especially scarce. In an 8-year follow-up of the CORDIS study, Melamed et al (7) found a trend towards a positive association between baseline noise exposure and the incidence of cardiovascular morbidity and mortality. In a register-based follow-up study, Virtanen \& Notkola (8) studied cardiovascular mortality among employed Finnish men and found that the most important occupational exposures were high workload, low control of one's own work, noise, and shift work. In both of these studies the associations between noise exposure and cardiovascular mortality were fairly weak, however.

In an attempt to cope with the annoyance caused by noise, a person may smoke more or adopt worse eating habits. Hypertension, high body-mass index (BMI), and smoking may all contribute markedly to the development

1 Helsinki Heart Study, Helsinki, Finland.

2 University of Tampere, Tampere, Finland.

3 Finnish Institute of Occupational Health, Helsinki, Finland.

Reprint requests to: Ms Hanna Virkkunen, Tampere School of Public Health, FIN-30104 University of Tampere, Tampere, Finland. [E-mail hanna.virkkunen@uta.fi] 
of CHD. In addition, as hypertension and BMI are part of the metabolic syndrome (9), their presence suggests that other factors of the syndrome like dyslipidemia, may be present or are to be expected (10). When occurring among persons exposed to environmental or occupational noise, hypertension may be a signal of increased susceptibility to CHD risk caused not only by hypertension as such, but also by various other factors. In the CORDIS study Melamed et al (11) found that noise annoyance was associated with serum lipid levels independently of the actual noise levels. This finding points to the importance of individual sensitivity in the association of noise with CHD risk factors.

Cardiovascular diseases have long been the leading cause of death among Finnish men of working age (1214). The age structure of western industrialized populations has been-and is still—changing, so that the proportion of retired people will continue to increase. Whether or not the increased CHD risk due to occupational exposure will persist long after the person is no longer exposed is a highly relevant question for an increasing number of people. To our knowledge, no studies have thus far been carried out that have focused on the delayed, postretirement effects of occupational exposure to noise on risk of CHD.

The aim of our study was to estimate the short- and long-term effects of occupational exposure to noise on the risk of CHD. For that purpose, we followed a cohort of industrially employed middle-aged men attending the first screening visit for the Helsinki Heart Study in 1982 (15). Information on the level of noise exposure for the participants was obtained by linkage to the FINJEM job-exposure matrix using the occupational code as the key (16). The outcome variable in this 18-year follow-up consisted of fatal or nonfatal coronary

Table 1. Noise exposure of the cohort members by occupational category.

\begin{tabular}{|c|c|c|c|c|}
\hline \multirow[t]{2}{*}{ Occupational category } & \multirow[t]{2}{*}{$\mathrm{N}$} & \multicolumn{3}{|c|}{$\begin{array}{l}\text { Prevalence of noise } \\
\text { exposure }(\%)\end{array}$} \\
\hline & & $\begin{array}{l}\text { Un- } \\
\text { ex- } \\
\text { pos- } \\
\text { ed }\end{array}$ & $\begin{array}{l}\text { Conti- } \\
\text { nuous } \\
\text { or im- } \\
\text { pulse } \\
\text { noise }\end{array}$ & $\begin{array}{c}\text { Both } \\
\text { types } \\
\text { of } \\
\text { noises }\end{array}$ \\
\hline 0-2 White-collar a & 1664 & 100 & $\cdot$ & . \\
\hline 3 Agriculture, forestry, commercial fishing & 236 & 83.9 & 16.1 & . \\
\hline 5 Transport and communications work & 209 & 50.2 & 49.8 & . \\
\hline 6 Manufacturing and related work ${ }^{b}$ & 1835 & 24.8 & 43.7 & 31.5 \\
\hline 7 Manufacturing and related work ${ }^{c}$ & 1929 & 30.1 & 69.8 & 0.1 \\
\hline Other & 132 & 67.4 & 32.6 & . \\
\hline
\end{tabular}

a $0=$ technical, physical, science, social science, humanistic and artistic work; 1 = administrative, managerial and clerical work; 2 = sales work

b Fine mechanical work; iron and metalware work; electrical work; wood work.

c Graphic work; glass, ceramic and clay work; chemical processing and related work. events and was obtained by linkage to populationbased registers.

\section{Study population and methods}

\section{Study population and follow-up via linkage to population registers}

The participants $(\mathrm{N}=6005)$ in our study were part of the participants $(\mathrm{N}=18939)$ from the first screening visit for the Helsinki Heart Study, a 5-year, randomized, double-blind, placebo-controlled, primary prevention trial of a lipid-lowering drug, gemfibrozil, on middle-aged men (40-56 years at entry) (15). The participants for the trial were selected via two successive screenings at two government agencies and five industrial companies. Those included in the trial had nonhigh-density lipoprotein cholesterol of $\geq 5.2 \mathrm{mmol} / \mathrm{l}$. After the 5-year trial, the participants (both the placebo and treatment groups) were invited to continue with the use of gemfibrozil as treatment until the end of 1995. About two-thirds of both groups continued on gemfibrozil; in other words, $23 \%$ of the participants in our present study were on gemfibrozil during the follow up.

In the present follow-up cohort, only industrially employed participants were included. The group comprised the occupational categories of iron and metal work, machine work in plants, woodworking, and chemical process work (table 1). The occupational categories were based on the three-digit occupational code used in the 1980 census, a Finnish version of the Nordic Classification of Occupations of 1965, which was obtained by record linkage with Statistics Finland. There are 10 major occupational categories in this classification. We considered classes 0,1 , and 2 to be white-collar work and classes 3 to 9 to be blue-collar work. Most $(72.3 \%)$ of the participants were blue-collar workers. The 40 men without an occupational code and 1 man with an unsuitable occupation (miner) were excluded. The four biggest occupational categories were paper and cardboard mill workers, sawyers, forklift operators and the like, and pulp mill workers.

The cardiac end points were obtained from the Hospital Discharge Register (kept by the National Research and Development Centre for Welfare and Health) and the Register of Deaths (kept by Statistics Finland). Several studies have found these registers to be accurate enough for epidemiologic purposes in studies of CHD $(17,18)$. Because of the long follow-up, the definition of CHD was based on codes 410-414 of the International Classification of Diseases (ICD), 8th and 9th versions for the years 1982-1995 and I20-I25 of the 10th version for the years 1996-1999. 
The cohort was followed from 1982 to the end of 1999 with a mean follow-up time of 15.9 years. Because of the long follow-up time, we have presented results with progressively longer follow-ups (until the end of 1991, 1995 and 1999). During the follow-up until the end of 1999 there had been 1166 cases of coronary events, of which 164 were fatal.

\section{Linkage to the job-exposure matrix for estimates of noise exposure}

FINJEM is a multipurpose information system that covers major occupational exposures occurring in Finland since 1945 (16). Agents, occupations, and calendar periods are the basic dimensions by which exposure is assessed. Exposure is characterized by the proportion of exposed (prevalence P) and the mean level of exposure among the exposed (level L) by occupation and period. The exposure estimates of the matrix are based on the judgment of some 20 experts from the Finnish Institute of Occupational Health. The bases for the estimates, definitions of agents, and measurement or survey data are documented in the FINJEM database.

In this study exposures to continuous and impulse noise from the period 1985-1994 were used. Impulse noise refers to noise that includes such high noise peaks that the equivalent noise dose in decibels underestimates the risk of noise-induced hearing loss. The prevalence and level were linked to the cohort data with the use of the three-digit occupational code. The prevalence for both types of noise exposure was assessed only qualitatively (either $0 \%$ or $100 \%$ ) so that, in the analyses, only the mean level of exposure was needed to quantify the exposure. The occupation-specific mean levels were based on data on noise measurements included in the NoiseScan database (19) of the Finnish Institute of Occupational Health. For continuous noise only exposures of 80 $\mathrm{dB}$ or more were reported, and people exposed to noise levels of 0-79 $\mathrm{dB}$ were considered to be unexposed. The mean level of the noise exposure was $80-100 \mathrm{~dB}$ for $2958(49.3 \%)$ men, and $580(9.7 \%)$ men were assigned as exposed to impulse noise. All of the men exposed to impulse noise were employed in manufacturing and related work (table 1). None of the white-collar workers were considered to be exposed to noise.

In the analyses, the noise variable was divided into the following three classes $(1=$ unexposed, $2=$ exposed to $80-85 \mathrm{~dB}, 3=$ exposed to $>85 \mathrm{~dB}$ ), and impulse noise was divided into two classes $[1=0$ (unexposed), $2=1$ (exposed)]. If the participant was exposed to impulse noise, he was also exposed to continuous noise. The combined noise variable consisted of three classes $(1=$ unexposed, 2 = exposed to continuous noise, $3=\mathrm{ex}-$ posed to continuous and impulse noise).
Exposure estimates of perceived physical workload and standing work from the period 1985-1994 were used. Perceived physical workload consisted of tasks in which the whole body was exerted in dynamic muscular work. Leisure time was not included. Standing work consisted of work done in a standing position. The posture of the trunk could vary. Leisure time was not included. The data on perceived workload and standing work originated from a national interview survey carried out in 1990. In the analyses the measure of exposure used was the product of the prevalence and the level.

\section{Blood pressure, serum lipids and some lifestyle factors}

Blood pressure was recorded from the right arm during the first screening visit using calibrated mercury sphygmomanometers with cuffs measuring $12 \times 40 \mathrm{~cm}$. The measurement was carried out with the participant in a sitting position before the blood sample was taken. Height was recorded to the nearest centimeter without shoes, and weight was recorded to the nearest kilogram, the participant wearing only light indoor clothing. Body mass index (BMI) was calculated as weight (kilograms) divided by height squared (meters ${ }^{2}$ ). The lipid measurements in this lipid modulation trial have been described in detail elsewhere (15).

Smoking habits were recorded by questionnaire at the beginning of the study (daily consumption of cigarettes), and a dichotomous variable (current smokers, nonsmokers) was used in the analyses. Ex-smokers were coded as nonsmokers.

\section{Statistical analysis}

The means of the systolic and diastolic blood pressure, the BMI, and the total serum cholesterol and the smoking percentages were used to compare possible differences between the groups for the combined noise variable. To test the trend in the means, we used an analysis-of-variance trend test for the continuous variables and the Cochran-Armitage trend test for the categorical variable.

To study the effect of noise exposure, we used Cox's proportional hazards models. Continuous noise was divided into three classes, impulse noise into two classes, and combined exposure to noise into three classes. To evaluate the possible mediating or confounding effect of other CHD risk factors, we added them to the model.

On entering the study, the men were 40-56 years of age, and at the end of the study they were 57-73 years of age. As the follow-up was long enough to allow for most of the participants to be retired before the end point, different follow-up times were used to study whether aging (retirement of participants) had an effect 
on CHD risk. The analyses were performed using the statistical packages Egret for Windows (Cytel Software Corporation, Cambridge, MA, USA) and SPSS 12.0.1 for Windows (SPSS Inc, Chicago IL, USA).

\section{Results}

\section{Noise and some risk factors for coronary heart disease}

The groups formed by categories of combined noise showed progressively increasing mean levels of systolic blood pressure and total serum cholesterol with an increasing level of noise among all of the workers (table 2). For those exposed to both types of noise, the mean level of systolic blood pressure was $142.0 \mathrm{~mm} \mathrm{Hg}$ compared with $139.3 \mathrm{~mm} \mathrm{Hg}$ for those unexposed to noise. The respective mean levels of the total serum cholesterol were $6.5 \mathrm{mmol} / \mathrm{l}$ and $6.3 \mathrm{mmol} / \mathrm{l}$. The same trend was also present for the mean levels of BMI, but not for the mean levels of the diastolic blood pressure. For the blue-collar workers, a statistically significant trend was found only for total serum cholesterol. The greatest differences were found for smoking in both groups of workers. There were $38.1 \%$ smokers among the workers exposed to both types of noise compared with $29.4 \%$ among the unexposed workers $(32.0 \%$ among unexposed blue-collar workers).

\section{Continuous and impulse noise and the risk of coronary heart disease}

The relative risk (RR) of CHD for all of the workers exposed to a continuous noise level of $>85 \mathrm{~dB}$ was significantly increased for all of the follow-up times (table 3 ). Compared with the relative risk of the unexposed men, those of all the workers were $1.45(\mathrm{P}<0.01), 1.42$ $(\mathrm{P}<0.01)$, and $1.48(\mathrm{P}<0.01)$ when they were followed to the end of 1991, 1995 and 1999, respectively. For the blue-collar workers, the risks were somewhat smaller, and that for the shortest follow-up was not significant. In both worker groups the relative risks showed a clear dose-response pattern for all of the follow-up times. Impulse noise was a significant risk factor for all of the workers when they were followed to the end of 1995 or 1999. When they were followed to the end of 1999, the relative risk was $1.34(\mathrm{P}<0.01)$.

The combined noise was a significant risk factor for all of the follow-up times (table 4). Those exposed to both continuous and impulse noise had relative risks of $1.38(\mathrm{P}=0.03), 1.47(\mathrm{P}<0.01)$, and $1.54(\mathrm{P}<0.01)$ for $\mathrm{CHD}$ when compared with those unexposed to noise. If age alone was added to the model, the risk estimates $(1.34,1.44$, and 1.51) were still statistically significant. Adding systolic blood pressure to the model changed the estimates slightly $(1.29,1.38$, and 1.46). When BMI, smoking, and total serum cholesterol were added to the model, combined noise exposure remained a significant risk factor for the 1995 and 1999 follow-up times. When adjusted for perceived physical workload, the results were similar to those when age and systolic blood pressure were added to the model. Adjustment for standing work did not materially change the risk estimates; for example, in the follow-up until the end of 1999, the relative risk for those exposed to both continuous and impulse noise was 1.55 (95\% CI 1.29-1.87) versus 1.54 (95\% CI 1.28-1.86) with no adjustment. However, the greatest effect on the relative risks shown in table 4 was found when adjustment was made for white- and bluecollar work-a crude proxy for social class. For example, in the follow-up until the end of 1999, the adjusted relative risks for noise in the group of all workers were 1 , 1.13 (95\% CI 0.97-1.30), and 1.28 (95\% CI 1.05-1.57).

Table 2. Systolic and diastolic blood pressure, body-mass index (BMI), total serum cholesterol, and smoking according to the noise variables for all workers and the blue-collar industrial employed workers.

\begin{tabular}{|c|c|c|c|c|c|c|c|c|c|c|c|c|c|c|}
\hline \multirow[t]{2}{*}{ Worker group } & \multicolumn{3}{|c|}{$\begin{array}{l}\text { Systolic blood } \\
\text { pressure (mmHg) }\end{array}$} & \multicolumn{3}{|c|}{$\begin{array}{l}\text { Diastolic blood } \\
\text { pressure }(\mathrm{mmHg})\end{array}$} & \multicolumn{3}{|c|}{$\begin{array}{c}\text { BMI } \\
\left(\mathrm{kg} / \mathrm{m}^{2}\right)\end{array}$} & \multicolumn{3}{|c|}{$\begin{array}{c}\text { Total serum } \\
\text { cholesterol (mmol/l) }\end{array}$} & \multicolumn{2}{|c|}{$\begin{array}{l}\text { Smoking } \\
\text { (yes) }\end{array}$} \\
\hline & $\mathrm{N}$ & Mean & SD & $\mathrm{N}$ & Mean & SD & $\mathrm{N}$ & Mean & SD & $\mathrm{N}$ & Mean & SD & $\mathrm{N}$ & $\%$ \\
\hline \multicolumn{15}{|l|}{ All workers } \\
\hline No noise & 3047 & 139.3 & 16.5 & 3047 & 89.9 & 10.1 & 3046 & 26.1 & 3.0 & 3043 & 6.3 & 1.2 & 3043 & 29.4 \\
\hline Continuous noise only & 2378 & 141.5 & 17.0 & 2378 & 90.4 & 10.2 & 2378 & 26.5 & 3.1 & 2377 & 6.3 & 1.1 & 2377 & 33.7 \\
\hline Both noise types ${ }^{a}$ & 580 & 142.0 & 17.3 & 580 & 90.6 & 10.3 & 580 & 26.4 & 3.2 & 580 & 6.5 & 1.2 & 580 & 38.1 \\
\hline Test for trend & \multicolumn{3}{|c|}{$P<0.01^{b}$} & \multicolumn{3}{|c|}{$P=0.13^{b}$} & \multicolumn{3}{|c|}{$P=0.01^{b}$} & \multicolumn{3}{|c|}{$P<0.01^{b}$} & \multicolumn{2}{|c|}{$P<0.01^{b}$} \\
\hline \multicolumn{15}{|l|}{ Blue-collar workers } \\
\hline No noise & 1383 & 141.2 & 16.7 & 1383 & 90.8 & 10.1 & 1383 & 26.4 & 3.1 & 1382 & 6.4 & 1.2 & 1383 & 32.0 \\
\hline Continuous noise only & 2378 & 141.5 & 17.0 & 2378 & 90.4 & 10.2 & 2378 & 26.5 & 3.1 & 2377 & 6.3 & 1.1 & 2377 & 33.7 \\
\hline Both noise types ${ }^{a}$ & 580 & 142.0 & 17.3 & 580 & 90.6 & 10.3 & 580 & 26.4 & 3.2 & 580 & 6.5 & 1.2 & 580 & 38.1 \\
\hline Test for trend & \multicolumn{3}{|c|}{$P=0.38^{b}$} & \multicolumn{3}{|c|}{$P=0.74^{b}$} & \multicolumn{3}{|c|}{$P=0.92^{b}$} & \multicolumn{3}{|c|}{$P=0.01^{b}$} & \multicolumn{2}{|c|}{$P=0.01^{c}$} \\
\hline
\end{tabular}

a Both continuous and impulse noise.

${ }^{b}$ Analysis-of-variance trend test (linear trend).

c Cochran-Armitage trend test. 
Table 3. Continuous and impulse noise as predictors of coronary heart disease (CHD) risk among all of the industrially employed men and the blue-collar group for different follow-up times. ( $\mathrm{RR}=$ relative risk, $95 \% \mathrm{Cl}=95 \%$ confidence interval)

\begin{tabular}{|c|c|c|c|c|c|c|c|c|c|c|}
\hline \multirow[t]{2}{*}{ Noise type } & \multicolumn{5}{|c|}{ All workers } & \multicolumn{5}{|c|}{ Blue-collar workers } \\
\hline & $\mathrm{N}$ & CHD events & $\mathrm{RR}^{\mathrm{a}}$ & $95 \% \mathrm{Cl}^{\mathrm{a}}$ & P-value a & $\mathrm{N}$ & CHD events & $\mathrm{RR}^{\mathrm{a}}$ & $95 \% \mathrm{Cl}^{\mathrm{a}}$ & P-value a \\
\hline \multicolumn{11}{|l|}{ Continuous } \\
\hline \multicolumn{11}{|c|}{ Follow- up in 1991} \\
\hline Unexposed & 3047 & 237 & 1 & . & . & 1383 & 132 & 1 & . & . \\
\hline $80-85 \mathrm{~dB}$ & 1721 & 173 & 1.32 & $1.08-1.60$ & 0.01 & 1721 & 278 & 1.06 & $0.85-1.33$ & 0.60 \\
\hline$>85 \mathrm{~dB}$ & 1237 & 137 & 1.45 & $1.18-1.79$ & $<0.01$ & 1237 & 206 & 1.17 & $0.92-1.49$ & 0.19 \\
\hline \multicolumn{11}{|c|}{ Follow-up in 1995} \\
\hline Unexposed & 3047 & 369 & 1 & . & . & 1383 & 193 & 1 & . & . \\
\hline $80-85 \mathrm{~dB}$ & 1721 & 278 & 1.37 & $1.18-1.60$ & $<0.01$ & 1721 & 278 & 1.17 & $0.98-1.41$ & 0.09 \\
\hline$>85$ bB & 1237 & 206 & 1.42 & $1.20-1.69$ & $<0.01$ & 1237 & 206 & 1.22 & $1.00-1.48$ & 0.05 \\
\hline \multicolumn{11}{|c|}{ Follow-up in 1999} \\
\hline Unexposed & 3047 & 509 & 1 & . & . & 1383 & 271 & 1 & . & . \\
\hline $80-85 \mathrm{~dB}$ & 1721 & 365 & 1.32 & $1.16-1.51$ & $<0.01$ & 1721 & 278 & 1.10 & $0.94-1.29$ & 0.23 \\
\hline$>85 \mathrm{bB}$ & 1237 & 292 & 1.48 & $1.28-1.71$ & $<0.01$ & 1237 & 206 & 1.23 & $1.05-1.46$ & 0.01 \\
\hline \multicolumn{11}{|l|}{ Impulse } \\
\hline \multicolumn{11}{|c|}{ Follow-up in 1991} \\
\hline Unexposed & 5425 & 486 & 1 & . & . & 3761 & 381 & 1 & . & . \\
\hline Exposed & 580 & 61 & 1.19 & $0.91-1.55$ & 0.21 & 580 & 61 & 1.04 & $0.79-1.36$ & 0.77 \\
\hline \multicolumn{11}{|c|}{ Follow-up in 1995} \\
\hline Unexposed & 5425 & 753 & 1 & . & . & 3761 & 577 & 1 & . & . \\
\hline Exposed & 580 & 100 & 1.27 & $1.03-1.56$ & 0.03 & 580 & 100 & 1.13 & $0.92-1.40$ & 0.25 \\
\hline \multicolumn{11}{|c|}{ Follow-up in 1999} \\
\hline Unexposed & 5425 & 1024 & 1 & . & . & 3761 & 786 & 1 & . & . \\
\hline Exposed & 580 & 142 & 1.34 & $1.12-1.60$ & $<0.01$ & 580 & 142 & 1.19 & $1.00-1.42$ & 0.06 \\
\hline
\end{tabular}

a Derived using a Cox proportional hazards model.

Table 4. Combined noise variable as a predictor of coronary heart disease (CHD) risk among all of the industrially employed men and the blue-collar group for different follow-up times. ( $\mathrm{RR}=$ relative risk, $95 \% \mathrm{Cl}=95 \%$ confidence interval, $\mathrm{BMI}=$ body mass index)

\begin{tabular}{|c|c|c|c|c|c|c|c|c|c|c|c|c|c|c|}
\hline \multirow[t]{3}{*}{ Worker group } & \multirow[t]{3}{*}{$\mathrm{N}$} & \multirow{3}{*}{$\begin{array}{l}\text { CHD } \\
\text { events }\end{array}$} & \multirow{2}{*}{\multicolumn{3}{|c|}{ Unadjusted }} & \multicolumn{9}{|c|}{ Adjusted } \\
\hline & & & & & & \multicolumn{3}{|c|}{$\begin{array}{l}\text { Age \& systolic } \\
\text { blood pressure }\end{array}$} & \multicolumn{3}{|c|}{$\begin{array}{l}\text { Age, systolic blood pres- } \\
\text { sure, total serum choles- } \\
\text { terol, smoking \& BMI }\end{array}$} & \multicolumn{3}{|c|}{$\begin{array}{l}\text { Perceived physical } \\
\text { workload }\end{array}$} \\
\hline & & & $\mathrm{RR}^{\mathrm{a}}$ & $95 \% \mathrm{Cl}^{\mathrm{a}}$ & $P$-value a & $\mathrm{RR}^{\mathrm{a}}$ & $95 \% \mathrm{Cl}^{\mathrm{a}}$ & $P$-value a & $\mathrm{RR}^{\mathrm{a}}$ & $95 \% \mathrm{Cl}^{\mathrm{a}}$ & $P$-value ${ }^{a}$ & $\mathrm{RR}^{\mathrm{a}}$ & $95 \% \mathrm{Cl}^{\mathrm{a}} \mathrm{F}$ & $P$-value a \\
\hline \multicolumn{15}{|l|}{ All workers } \\
\hline \multicolumn{15}{|l|}{ Follow- up in 1991} \\
\hline No noise & 3047 & 237 & 1 & . & . & 1 & . & . & 1 & . & . & 1 & . & \\
\hline Continuous noise & 2378 & 249 & 1.37 & $1.15-1.64$ & $<0.01$ & 1.31 & $1.10-1.56$ & $<0.01$ & 1.27 & $1.06-1.52$ & 0.01 & 1.31 & $1.09-1.58$ & $<0.01$ \\
\hline Both noise types ${ }^{b}$ & 580 & 61 & 1.38 & $1.04-1.82$ & 0.03 & 1.29 & $0.97-1.70$ & 0.08 & 1.16 & $0.88-1.54$ & 0.30 & 1.29 & $0.97-1.72$ & 0.08 \\
\hline \multicolumn{15}{|c|}{ Follow-up in 1995} \\
\hline No noise & 3047 & 369 & 1 & . & . & 1 & . & . & 1 & . & . & 1 & . & \\
\hline Continuous noise & 2378 & 384 & 1.37 & $1.19-1.59$ & $<0.01$ & 1.31 & $1.14-1.52$ & $<0.01$ & 1.28 & $1.11-1.48$ & $<0.01$ & 1.34 & $1.15-1.55$ & $<0.01$ \\
\hline Both noise types ${ }^{b}$ & 580 & 100 & 1.47 & $1.18-1.84$ & $<0.01$ & 1.38 & $1.11-1.73$ & $<0.01$ & 1.26 & $1.01-1.58$ & 0.04 & 1.41 & $1.13-1.78$ & $<0.01$ \\
\hline \multicolumn{15}{|l|}{ Follow-up in 1999} \\
\hline No noise & 3047 & 509 & 1 & . & & 1 & & & 1 & & & 1 & & \\
\hline Continuous noise & 2378 & 515 & 1.35 & $1.19-1.53$ & $<0.01$ & 1.29 & $1.15-1.46$ & $<0.01$ & 1.27 & $1.13-1.44$ & $<0.01$ & 1.30 & $1.14-1.48$ & $<0.01$ \\
\hline Both noise types ${ }^{b}$ & 580 & 142 & 1.54 & $1.28-1.86$ & $<0.01$ & 1.46 & $1.21-1.76$ & $<0.01$ & 1.35 & $1.12-1.62$ & $<0.01$ & 1.46 & $1.20-1.77$ & $<0.01$ \\
\hline \multicolumn{15}{|l|}{ Blue-collar workers } \\
\hline \multicolumn{15}{|l|}{ Follow- up in 1991} \\
\hline No noise & 1383 & 132 & 1 & . & . & 1 & . & . & 1 & & . & 1 & 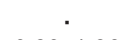 & \\
\hline Continuous noise & 2378 & 249 & 1.11 & $0.90-1.37$ & 0.34 & 1.11 & $0.90-1.38$ & 0.32 & 1.13 & $0.92-1.40$ & 0.25 & 1.10 & $0.89-1.36$ & 0.38 \\
\hline Both noise types ${ }^{b}$ & 580 & 61 & 1.11 & $0.82-1.51$ & 0.49 & 1.10 & $0.81-1.48$ & 0.56 & 1.04 & $0.77-1.41$ & 0.79 & 1.09 & $0.80-1.48$ & 0.58 \\
\hline \multicolumn{15}{|l|}{ Follow-up in 1995} \\
\hline No noise & 1383 & 193 & 1 & . & . & 1 & . & . & 1 & . & . & 1 & . & \\
\hline Continuous noise & 2378 & 384 & 1.17 & $0.99-1.40$ & 0.07 & 1.18 & $0.99-1.40$ & 0.06 & 1.19 & $1.00-1.42$ & 0.04 & 1.17 & $0.98-1.39$ & 0.08 \\
\hline Both noise types ${ }^{b}$ & 580 & 100 & 1.26 & $0.99-1.60$ & 0.06 & 1.24 & $0.98-1.58$ & 0.08 & 1.18 & $0.93-1.51$ & 0.17 & 1.25 & $0.98-1.59$ & 0.08 \\
\hline \multicolumn{15}{|l|}{ Follow-up in 1999} \\
\hline No noise & 1383 & 271 & 1 & . & . & 1 & . & . & 1 & 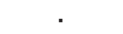 & . & 1 & . & \\
\hline Continuous noise & 2378 & 515 & 1.13 & $0.97-1.30$ & 0.11 & 1.13 & $0.98-1.31$ & 0.10 & 1.15 & $0.99-1.33$ & 0.07 & 1.12 & $0.97-1.30$ & 0.14 \\
\hline Both noise types ${ }^{b}$ & 580 & 142 & 1.29 & $1.05-1.57$ & 0.02 & 1.28 & $1.04-1.56$ & 0.02 & 1.22 & $0.99-1.49$ & 0.06 & 1.27 & $1.03-1.55$ & 0.02 \\
\hline
\end{tabular}

a Derived using a Cox proportional hazards model.

${ }^{b}$ Both continuous and impulse noise. 
It should be noted that these estimates were very close to those obtained for the blue-collar workers (table 4). This finding was to be expected since the white-collar workers were not at all exposed to occupational noise.

Among the blue-collar workers, the combined noise exposure was a significant risk factor only when the follow-up lasted to the end of 1999. In this case, those exposed to both types of noise had a relative risk of 1.29 $(\mathrm{P}=0.02)$ as compared with those who were unexposed. The relative risk (RR 1.22) was almost statistically significant $(\mathrm{P}=0.06)$ even when all the covariates (age, systolic blood pressure, total serum cholesterol, smoking, and BMI) were added to the model. Adjustment for perceived physical workload or standing work did not essentially change the estimates.

\section{Effect of gemfibrozil treatment on the association between noise and coronary heart disease}

Adjustment for gemfibrozil did not essentially change the risk estimates for the noise levels. However, when we made a separate analysis for this small, dyslipidemic group that was receiving treatment, the point estimates for the relative risks at the subsequent noise levels were $1.00,1.53$, and 1.28 compared with the unadjusted values of $1.00,1.37$, and 1.47 in the all-participant group during the same follow-up until the end of 1995. A similar drop in risk for the combined noise level was found when age, systolic blood pressure, total serum cholesterol, and BMI were adjusted for (table 4).

\section{Does the effect of noise on the risk of coronary heart disease persist after retirement?}

The age range of the participants was $40-56$ years at the beginning of the study, and at the end of the study it was 57-63 years. The median age of retirement for Finnish workers (eg, in 1996) was 60.1 years (20), and the obligatory age of retirement was 65 years. To study the carry-over effect of noise exposure on those who had retired, we restricted the follow-up of the participants to start from when they turned 60 or 63 years of age.

For both the blue-collar workers and all of the workers combined, the risk estimates were higher for the older population (table 5). In the group of all workers the relative risk for combined noise was $1.50(\mathrm{P}<0.01$, adjusted for age, systolic blood pressure, BMI, total serum cholesterol, and smoking), and for the blue-collar workers the corresponding risk was $1.31(\mathrm{P}=0.08)$ when followed from the age of 60 years. However, in both groups, only those exposed to the combination of continuous and impulse noise had an increased CHD risk, not those exposed to continuous noise only. When the workers were followed from the age of 63 years, the corresponding risks were $1.89(\mathrm{P}<0.01)$ and 1.53

Table 5. Combined noise variable as a predictor of risk for 60-year-old and 63-year-old men among all the industrially employed men and the blue-collar group. ( $\mathrm{RR}=$ relative risk, $95 \% \mathrm{Cl}=95 \%$ confidence interval)

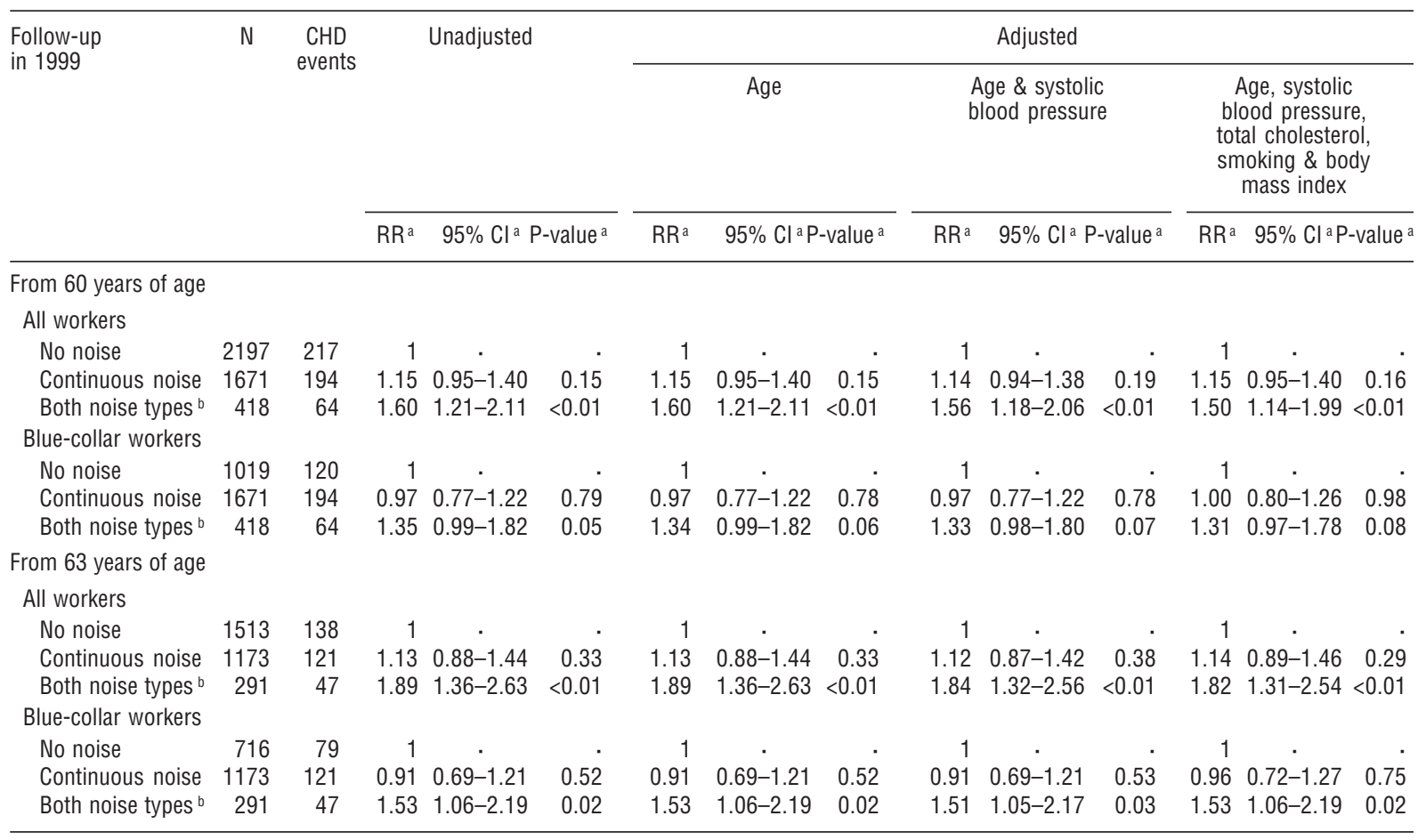

a Derived using a Cox proportioned hazards model.

b Both continuous and impulse noise. 
$(\mathrm{P}=0.02)$, respectively. It is noteworthy that the corresponding estimates for the long-term follow-up of the whole cohort were $1.35(\mathrm{P}<0.01)$ and $1.22(\mathrm{P}=0.06)$ (table 4).

\section{Discussion}

The results of our 18-year follow-up study of an industrial cohort showed that CHD risk was moderately but consistently elevated by occupational noise exposure exceeding $80 \mathrm{~dB}$ and that the relative risks showed a clear dose-response pattern with increasing levels of noise exposure. Furthermore, the point estimates of the relative risks were higher when the follow-up time was extended to the end of 1999, and it was even higher when the follow-up was limited to start when the participants had reached the age of 60 years. The risk thus seemed to persist even when the participants were 60 to 73 years of age (ie, when most of them were retired). The estimates for the CHD risk associated with the exposure to continuous and impulse noise varied between $1.22(\mathrm{P}=0.06)$ and $1.54(\mathrm{P}=0.001)$ depending on the reference group used and the covariates adjusted for.

\section{Problems with an appropriate reference group with respect to occupational class and noise exposure}

When studying the effect of noise exposure on mean levels of lifestyle factors and blood pressure in a crosssectional situation or when studying longitudinally its effect on CHD risk, we analyzed the data both as an entity and separately among blue-collar workers. As seen in table 2 , all of the white-collar workers belonged to the unexposed group so that their inclusion or exclusion had an impact on the reference group and thereby on the relative risks. All of the differences between the groups of unexposed and exposed to both types of noise were greater if the white-collar workers were included in the study population; the difference was found both when the means of the lifestyle factors or the CHD risks were studied. It is evident that factors other than noise exposure may contribute to the differences in lifestyle factors and CHD risk between white-collar and bluecollar workers, and it would thus be reasonable to restrict the analysis to blue-collar workers only. However, the cut-off point for noise exposure was set at $80 \mathrm{~dB}$, and it is probable that the unexposed blue-collar group actually entailed more noise exposure than the whitecollar group and thus formed a less optimal reference group due to poorer exposure contrast. The "true" relative risk of CHD may therefore lie somewhere between the estimates obtained when first the all-participant group was analyzed and then the blue-collar group.

\section{Confounders or mediators of effect with respect to blood pressure and lifestyle factors}

Blood pressure, BMI, total cholesterol, and smoking were all more or less closely related to noise exposure in our study, and they are also classic risk factors for CHD. On the one hand, they are thus potential confounders for the noise-CHD association and should be adjusted for. On the other hand, there prevails a fairly high consensus concerning the effect of noise on blood pressure (hypertension) (21), and the hypothesis that at least hypertension, but possibly also lifestyle factors, also mediate the effect of noise on CHD risk seems plausible. Therefore adjustment for them may lead to overcontrol (22) and should be avoided, unless the aim of the adjustment was to see what part of the effect goes through the covariate in question. Faced with the question "confounders or mediators of effect" we would answer "both", especially when the study group consisted of both white-collar and blue-collar workers. We presented different adjustments to enable comparisons (table 4). For example, perceived physical workload is related to noise exposure and may itself be a risk factor for CHD, representing thus a putative confounder. When added to the model, it decreased the risk estimates approximately to the same degree as age and systolic blood pressure together. The greatest decrease in the risk estimates was found-also among the blue-collar workers-when age and the factors related to the metabolic syndrome, systolic blood pressure, BMI and smoking, and total serum cholesterol were simultaneously added to the model. We can speculate that this finding signals that a considerable part of the noise-CHD effect goes through the noise-stress-metabolic syndrome pathway (23-25).

In this context, it is interesting to compare the results from our long-term follow-up of the elderly participants with the findings of Melamed et al (7), who found that annoyance caused by noise was associated with serum lipid levels independently of the actual noise levels and that the effect of noise exposure on blood pressure depended on job complexity (6). In our longterm follow-up among the elderly, noise was a risk factor only if it involved impulse noise. It seems plausible that especially that kind of noise is annoying and disturbing. The finding that the relative risk of the group with exposure to both continuous and impulse noise was considerably decreased when the factors related to the metabolic syndrome were added to the model also supports the hypothesis that the effect of noise on CHD risk goes via the development of the metabolic syndrome. Similarly, the finding that the relative risk of the corresponding group of those treated with gemfibrozil was only 1.28 versus 1.54 for the all-participant group leads to the same conclusion, as gemfibrozil is known to 
decrease CHD risk, especially among those with metabolic syndrome (26). However, the possibility remains that the decrease in CHD risk due to noise exposure was partly due to the elimination of the effect of confounding factors.

\section{Role of occupational noise among other occupational risk factors for coronary heart disease}

In their study on the work environment of Danish shift and day workers, Boggild et al (27) observed that a high proportion of shift workers was exposed to several other occupational risk factors, for example, noise, heat, and physical workload in addition to various psychosocial factors. They expressed the concern that "The possibility remains that shift work acts as a proxy for other work-related risk factors for CVD and that the risk of shift work is explained by these other risk factors [p 98]". Obviously, the reasoning may also be reversed, and we can ask whether the risk associated with noise exposure could be explained by, for example, physical workload or shift work. Indeed, in our study, part of the risk associated with noise exposure was explained by concurrent physical workload, but the workload did not, by any means, explain all of it.

Our data did not include information on shift work, but in another ongoing study on the joint effects of shift work and occupational noise on the risk of CHD, we used a subpopulation of the currently used population, and, for these workers, information on shift work was available. In that study we divided the data according to the four groups of shift-,noise-; shift-,noise+; shift+,noise-; and shift+,noise+ and compared the risks in these groups. We found that exposure to continuous and impulse noise involved a significantly increased CHD risk even without shift work and even when only blue-collar workers were included in the analysis.

\section{Strengths and limitations of the study}

The design of our study has both strengths and weaknesses. Among the strengths, we can note that it is a follow-up study of a well-defined, large industrial population with relevant background variables available. The information on noise exposure was obtained from the FINJEM, a job-exposure matrix constructed by industrial hygienists based on Finnish data. The matrix evidently does not provide exposure information on an individual level, but only information for the occupational group in question. In large-scale studies it would, however, be impossible to follow the exposure of each participant (16). The effect of group-based exposure information is that the exposed group may contain unexposed persons (and vice versa), and this situation may tend to mask the actual risk. The outcome variable
(CHD) was obtained from Finnish population registers, which are known for their reliability $(17,18)$.

One drawback of our study was that we had only cross-sectional information on explanatory variables such as occupation and blood pressure. The occupational categories were based on the three-digit occupational code used in the 1980 census. However, the stability for most of the occupations was so high that cross-sectional information on occupation represents life-long occupational history fairly well (28). This situation is especially true for aged populations, in which the turnover between occupations is low. Another drawback was that we did not have the years of exposure available for the analysis and, especially, the year of retirement. In any case, about half of the participants were 65-73 years of age at the end of the study. During the last 5 years of the follow-up, a considerable proportion of the study population must have retired and therefore was removed from occupational exposure. One could expect that this situation would result in a flattening of the pattern of risk, particularly in the follow-up analysis of those aged $\geq 60$ years. The results, however, showed even higher risk estimates for the elderly, suggesting thus that CHD risk persists several years after the end of occupational noise exposure.

One measurement of blood pressure is generally considered insufficient for predicting the future development of blood pressure or the risk of CHD. The rather small change in the risk estimate for noise when systolic blood pressure was added to the model can be explained by the incompleteness of this variable rather than by the lack of importance.

In conclusion, in our long-term follow-up of industrially employed men, occupational exposure to noise, especially to impulse noise, was associated with a moderate, but statistically significant increased risk of CHD that persisted even when the workers had passed the age of retirement.

\section{Acknowledgments}

This study was supported by the Kalle Kaihari Heart Research Fund and the Scientific Foundation of the City of Tampere.

We would like to thank Virginia Mattila, Language Centre, University of Tampere, for her revision of the English language of the manuscript.

\section{References}

1. van Dijk FJH. Non-auditory effects of noise in industry, II: a review of the literature. Int Arch Occup Environ Health 
1986;58:325-32.

2. Passchier-Vermeer W, Passchier WF. Noise exposure and public health. Environ Health Perspect 2000;108 suppl 1:12331.

3. Ta-Yuan C, Ruei-Man J, Chiu-Sen W, Chang-Chuan C. Effects of occupational noise exposure on blood pressure. J Occup Environ Med 2003;45:1289-96.

4. Stansfeld SA, Haines MM, Burr M, Berry B, Lercher P. A review of environmental noise and mental health. Noise Health 2000;2(8):1-8.

5. van Kempen EE, Kruize H, Boshuizen HC, Ameling CB, Staatsen BA, de Hollander AE. The association between noise exposure and blood pressure and ischemic heart disease: a meta-analysis. Environ Health Perspect 2002;110(3):307-17.

6. Melamed S, Fried Y, Froom P. The interactive effect of chronic exposure to noise and job complexity on changes in blood pressure and job satisfaction: a longitudinal study of industrial employees. J Occup Health Psychol 2001;6(3):182-95.

7. Melamed S, Kristal-Boneh E, Froom P. Industrial noise exposure and risk factors for cardiovascular disease: findings from the CORDIS Study. Noise Health 1999;1(4):49-56.

8. Virtanen SV, Notkola V. Socioeconomic inequalities in cardiovascular mortality and the role of work: a register study of Finnish men. Int J Epidemiol 2002;31(3):614-21.

9. Reaven GM. Banting lecture 1988: role of insulin resistance in human disease. Diabetes 1988;37(12):1595-607.

10. Hopkins PN, Hunt SC, Wu LL, Williams GH, Williams RR. Hypertension, dyslipidemia, and insulin resistance: links in a chain or spokes on a wheel? [review]. Curr Opin Lipidol 1996;7(4):241-53

11. Melamed S, Froom P, Kristal-Boneh E, Gofer D, Ribak J. Industrial noise exposure, noise annoyance, and serum lipid levels in blue-collar workers-the CORDIS Study. Arch Environ Health 1997;52(4):292-8.

12. Aromaa A, Koskinen S, Huttunen J, editors. Health in Finland. Helsinki: National Public Health Institute, Ministry of Social Affairs and Health; 1999.

13. Valkonen T, Martelin T, Rimpelä A. Socio-economic mortality differences in Finland 1971-85. Helsinki: Central Statistical Office of Finland; 1990. Studies 176.

14. Valkonen T, Martelin T, Rimpelä A, Notkola V, Savela S. Socio-economic mortality differences in Finland 1981-90. Helsinki: Statistics Finland; 1993. Official Statistics of Finland, Population 1.

15. Frick MH, Elo O, Haapa K, Heinonen OP, Heinsalmi P, Helo $\mathrm{P}$, et al. The Helsinki Heart Study: primary prevention trial with gemfibrozil middle-aged men with dyslipidemia: safety of treatment, changes in risk factors, and incidence of coro- nary heart disease. N Engl J Med 1987;317:1237-45.

16. Kauppinen T, Toikkanen J, Pukkala E. From cross-tabulations to multipurpose exposure information systems: a new jobexposure matrix. Am J Ind Med 1998;33:409-17.

17. Palomäki $P$, Miettinen $H$, Mustaniemi $H$, Lehto S, Pyörälä K, Mähönen M, et al. Diagnosis of acute myocardial infarction by MONICA and FINMONICA diagnostic criteria in comparison with hospital discharge diagnosis. J Clin Epidemiol 1994:47:659-66.

18. Pietilä K, Tenkanen L, Mänttäri M, Manninen V. How to define coronary heart disease in register-based follow-up studies: experience from the Helsinki Heart Study. Ann Med 1997;29:253-9.

19. Pyykkö I, Toppila E, Starck J, Juhola M, Auramo Y. Database for a hearing conservation program. Scand Audiol 2000; 29:52-8.

20. Finnish Centre for Pensions, The Social Insurance Institution. Statistical yearbook of pensioners in Finland 1996. Helsinki: Finnish Centre for Pensions, The Social Insurance Institution; 1997.

21. Stansfeld SA, Matheson MP. Noise pollution: non-auditory effects on health. Br Med Bull 2003;68:243-57.

22. Babisch W. Epidemiological studies of the cardiovascular effects of occupational noise-a critical appraisal. Noise Health 1998;1(1):24-39.

23. Melamed S, Bruhis S. The effects of chronic industrial noise exposure on urinary cortisol, fatigue and irritability: a controlled field experiment. J Occup Environ Med 1996;38(3):2526.

24. Babisch W. Stress hormones in the research on cardiovascular effects of noise. Noise Health 2003;5(18):1-11.

25. Brunner EJ, Hemingway H, Walker BR, Page M, Clarke P, Juneja M, et al. Adrenocortical, autonomic, and inflammatory causes of the metabolic syndrome: nested case-control study. Circulation. 2002;106(21):2659-65.

26. Tenkanen L, Manttari M, Manninen V. Some coronary risk factors related to the insulin resistance syndrome and treatment with gemfibrozil: experience from the Helsinki Heart Study. Circulation 1995;92:1779-85.

27. Boggild H, Burr H, Tuchsen F, Jeppesen HJ. Work environment of Danish shift and day workers. Scand J Work Environ Health 2001;27(2):97-105.

28. Kolari R. Occupational mobility in Finland 1975/1980/1985. Helsinki: Central Statistical Office of Finland; 1989. Studies 160

Received for publication: 8 October 2004 